\title{
The Effect of COVID-19 Pandemic on Emitted PM 2.5 in Urban Road Networks: Using Loop Data and \\ Kriging Method for Passenger Cars in the Central Part of the City of Lodz
}

Aerosol and Air Quality Research

Special Issue:

Special Issue on Air Quality in a Changed World: Regional, Ambient, and Indoor Air Concentrations from the COVID to Post-COVID Era (IV)

\section{OPEN ACCESS}

Received: November 14, 2021 Revised: January 29, 2022 Accepted: March 3, 2022

\section{${ }^{*}$ Corresponding Author:}

a_sahebgharani@iut.ac.ir

\section{Publisher:}

Taiwan Association for Aerosol Research

ISSN: $1680-8584$ print ISSN: 2071-1409 online

(c) Copyright: The Author(s) This is an open access article distributed under the terms of the Creative Commons Attribution License (CC BY 4.0), which permits unrestricted use, distribution, and reproduction in any medium, provided the original author and source are cited.

\author{
Marta Borowska-Stefańska ${ }^{(1)}{ }^{1}$, Michał Kowalski ${ }^{\circledR 1}{ }^{1}$, Paulina Kurzyk ${ }^{1}$, \\ Alireza Sahebgharani ${ }^{2}$, Szymon Wiśniewski ${ }^{1}$
}

\author{
${ }^{1}$ Institute of the Built Environment and Spatial Policy, Faculty of Geographical Sciences, \\ University of Lodz, 90-142 Lodz, Poland \\ ${ }^{2}$ Department of Transportation Engineering, Isfahan University of Technology, Isfahan 84156- \\ 83111, Iran
}

\section{ABSTRACT}

In this paper, the effect of the COVID-19 pandemic on the emission of PM2.5 generated by passenger cars is investigated. First, traffic data collected from the inductive loop sensors is analyzed. Second, the traffic flow for the whole network system is estimated using an isometric transformed network and the Euclidean space, and the representative one is selected. Then, an emission model is presented for measuring the level of $\mathrm{PM}_{2.5}$ emissions by the passenger cars, and the integration process is given. Finally, the model is implemented on the central part of the city of Lodz, and the value of emissions before and after the COVID-19 pandemic is measured. Finally, the outputs and the process of the model calibration are depicted. Results show that before the pandemic, $\mathrm{PM}_{2.5}$ pollution was highly concentrated in the center and peripheral parts of the area under consideration, and it would gradually drop outside rush hours and grow at peak hours. After the lockdown, the pollution load throughout the whole area, and across its central parts in particular, decreased dramatically. Outputs also illustrate that restrictions not only lower the car-induced $\mathrm{PM}_{2.5}$ but also have a significant effect on the impact zones, areas affected by the pollutants. Another finding is that although the COVID-19 outbreak clearly poses a serious threat to life and health, it has had an exceptionally positive impact on the natural environment, becoming an unconventional mechanism for its restoration.

Keywords: COVID-19 pandemic, Transportation emission, Inductive loop data, Kriging method, Traffic flow

\section{INTRODUCTION}

Air pollution can be generated by different sources (e.g., fireplaces and human activities), among them, vehicles are considered as the main outdoor source of pollution in the urban settlements where combustion and consumption of fuels cause deterioration of both health and air quality (Agudelo-Castañeda et al., 2013; Gualtieri et al., 2015; de Fatima Andrade et al., 2017; de Almeida Albuquerque et al., 2018).

Several pieces of research can be found in the literature that attempted to analyze the linkage between road traffic and air pollution (Abdul-Wahab and Fadlallah, 2014; Borge et al., 2018; Charabi et al., 2018; Izquierdo et al., 2020; Shahbazi and Hosseini, 2020). For example, Shahbazi et al. (2017) indicated that traffic flow has a significant contribution to the air pollution of mega-cities, and mentioned that considering traffic restricted zones can have positive impacts on the air pollution reduction. Guttikunda et al. (2019) reported that transportation is the major source of pollution 
in the Bengaluru region. Pinto et al. (2020) modeled dispersion of the pollutions produced by the traffic flows and stated that air pollution is associated with vehicular movement in Belo Horizonte city in Brazil. It should be noted that although these studies depicted the connection between air pollution and vehicular movement, analyzing pollution emission of the traffic is problematic because of some reasons. First, as the recorded data in the urban environments are related to many sources (e.g., power plants and residential activities) (Duque et al., 2016; Pan et al., 2016), recognizing the share and distribution of pollutions emitted from the traffic can be difficult. Second, pollution generated by traffic flows in each link of a street network cannot be distinguished the from monitoring stations directly because of the distance between the stations and the network segments (Pasquier and André, 2017; Rossi et al., 2020). Third, due to the delays that might be occurred in the data collection process, temporal records are associated with lags which add more complexity to the vehicular pollution emission analysis (Shi et al., 2018; Rossi et al., 2020). Nevertheless, regarding the fact that models provide helpful tools to estimate pollution concentration and dispersion (Holnicki et al., 2016; Khan and Hassan, 2020), vehicular emissions have been computed in various studies (Jenkins et al., 1970; Clougherty et al., 2008; Elangasinghe et al., 2014; Perez-Martinez and Miranda, 2015; Pan et al., 2016; Shi et al., 2018; Qu et al., 2019). These studies calculated the vehicular emissions by focusing on the flow data collected for a subset of links (e.g., a certain road or highway) in a network. However, the effect of flow distribution in the entire network was not included in the modeling framework.

On March 11, 2020, the COVID-19 pandemic was announced by the World Health Organization (WHO) (WHO, 2020). Countries have taken various actions to control and confront this infectious disease such as: staying at home and keeping social distancing (Şahin, 2020). Furthermore, many regions imposed lockdown and movement restrictions as one of the most effective measures for minimizing the risk of virus contractions (Le et al., 2021). Execution of the lockdown policy not only has had implications for curbing the pandemic but also highly impacted the transportation system worldwide (Ranjbari et al., 2021), and consequently, improvement of the air quality in different parts of the world (Gautam, 2020; Chen et al., 2021).

Aside from the city and regional scale studies which considered the effect of lockdowns on the pollution emitted by the transportation system (Gualtieri et al., 2020; Şahin, 2020; Wang et al., 2020a; Chen et al., 2021; Le et al., 2021), some research has been done at the intra-urban level. Xiang et al. (2020) conducted research to examine the impacts of the COVID-19 responses on traffic-related air pollution utilizing flow data collected by the loop sensors for several links in the street network along with the pollution data gathered from a roadside monitoring station. Rossi et al. (2020) carried out a study to evaluate the effect of the traffic on air pollution before and after the COVID-19 lockdown using data of two traffic detectors and two closest monitoring systems. Ravina et al. (2021) analyzed the dispersion of traffic-induced pollution during the lockdown period based on the traffic data obtained from 31 sensors. These pieces of research mainly applied the data recorded by the detectors and monitoring stations for a set of places without considering the distribution of vehicles in the street network, which is critical for air pollution analysis at the intra-urban scale (Gualtieri et al., 2020). This way, it can be inferred that flow of each link in a street network acts as a source of pollution.

Basically, traffic data can be acquired by origin-destination survey, traffic modeling software, and traffic data prediction. The latter one combined with smart data (e.g., loop sensors and real-time location-based data) is an alternative and low-cost approach to the survey and commercial software application and can provide satisfactory inputs for vehicular emission analysis (Fu et al., 2017; Pinto et al., 2020). Spatiotemporal flow prediction can be implemented by the utilization of spatial analysis tools, namely, Kriging interpolations (Selby and Kockelman, 2011; Yang et al., 2018), Thiessen polygons (Gómez et al., 2018), geographical regressions (Song et al., 2018), spatial autoregressive models (Sun et al., 2018), and neural networks (Fu et al., 2017). Considering the potentials of the traffic prediction and spatial analysis tools for the vehicular emission analysis, recently, Pinto et al. (2020) applied spatial analysis interpolation in a Euclidian space together with an air pollution model to analyze emissions and air pollution reduction strategies. However, it should be noted that the predictive spatial models are sensitive to the distance of entities scattered in the environment, and for variables such as traffic flow, network-based distances can be calculated as well as the Euclidian ones. This way, alongside the latter, the network-based distances need to be computed to check which one is more representative for the application of spatial analysis techniques. 
Therefore, based on the above-mentioned literature, it can be indicated that evaluating the effect of lockdown policy execution on traffic-related emissions by considering traffic flows in the entire links of a street network is an important research area. Notwithstanding the existing research dealing with the issue of analyzing transportation system pollutions before and after the lockdowns, there is still a gap in the body of knowledge to assess the traffic-based emissions while taking the flow of each link of a street network into account. Since spatial analysis techniques provide useful, efficient, and low-cost tools for the estimation of flows in the space, this study aims at analyzing the effect of lockdowns imposed on the city of Lodz, the most congested urbanized area in Poland (TomTom, 2021), by computing flow of each link in its street network. In addition, due to the potential and availability of the smart data in the city of Lodz, the evaluation can be carried out at the hourly temporal resolution by testing both Euclidian and network-based spaces that have not been studied in the previous air pollution analysis research (e.g., Pinto et al. (2020)).

The rest of this article is organized as follows. First, the study area and the data used for analysis are described. Second, traffic flow estimation and emission models along with the pollutant under consideration are explained and justified. Third, outputs of the models together with the research limitations are given and discussed, and finally, conclusions are drawn.

\section{MATERIALS AND METHODS}

In this part of the article, firstly, study area and data used for the analysis purposes are described. Then, two main components of the assessment framework (i.e., flow and emission models) are explained. Finally, the integrated structure applied for producing the results is represented.

\subsection{Case Study and Data}

Even though the research area discussed in the paper constitutes merely $13 \%$ of the administrative territory of Lodz, it is home to over $42 \%$ of the city's population, which, according to the Polish Central Statistical Office, amounted to 672,185 as of $31 / 12 / 2020$. The analyzed area lies in the city's central part, within the inner ring road, and encompasses the Urban Core Zone with adjacent neighborhoods. The spatio-functional (inner and outer) borders of the area are roads that form the city's major transport arteries (fast traffic trunk roads). As shown by Borowska-Stefańska et al. (2019), these roads are exposed to the highest traffic load. Since the local network consists primarily (almost 90\%) of low-class roads: other, local, and service, numerous issues are reported there, including extreme traffic load and congestion.

The current spatial development of Lodz, a former industrial city, is strongly conditioned by its history and cultural layering, which is particularly true of the selected study area, namely the city center in its broadest sense. Within the boundaries of this area, there is the greatest number of stately residential and factory buildings as well as regularly and most fully developed quarters (Dankowska, 2016). Due to its location, the researched area boasts high development density (amounting to $25.91 \%$ of the city's total built-up area) and a large number of business entities (including retail units and shopping centers, which constitute $60.91 \%$ and $33.33 \%$ of all city's facilities of this type respectively). In consequence, the area is exposed to extensive use that causes many urbanistic and environmental issues, e.g., air pollution (Fig. 1). It is therefore not only the area with the highest population density in the city, but it is also characterized by a high density of urban functions, both local and metropolitan, including trade, services, administration, but also recreation or culture. Therefore, the study of air quality in this area is particularly important.

The sub-system of private car transport plays a crucial role in the structure of transport in Lodz, which, according to the 2020 TomTom Traffic Index (TomTom, 2021), was the most congested city in Poland. Movement of the vehicles in Lodz can be obtained from the local Intelligent Transport System (ITS). Under the formal definition of ITS in the Polish Act on Public Roads, it is a system uses information and communication technologies not only in the field of road transport, covering infrastructure, vehicles and its users, but also in the field of traffic management as well as for interfaces with other modes of transport. In accordance with the information of the General Directorate for National Roads and Motorways in Poland (GDDKiA), Intelligent Transport System solutions are used to achieve specific benefits (e.g., improved travel safety, reduced travel times, more efficient use of the transport network) regardless of the spatial scale covered by the system. 

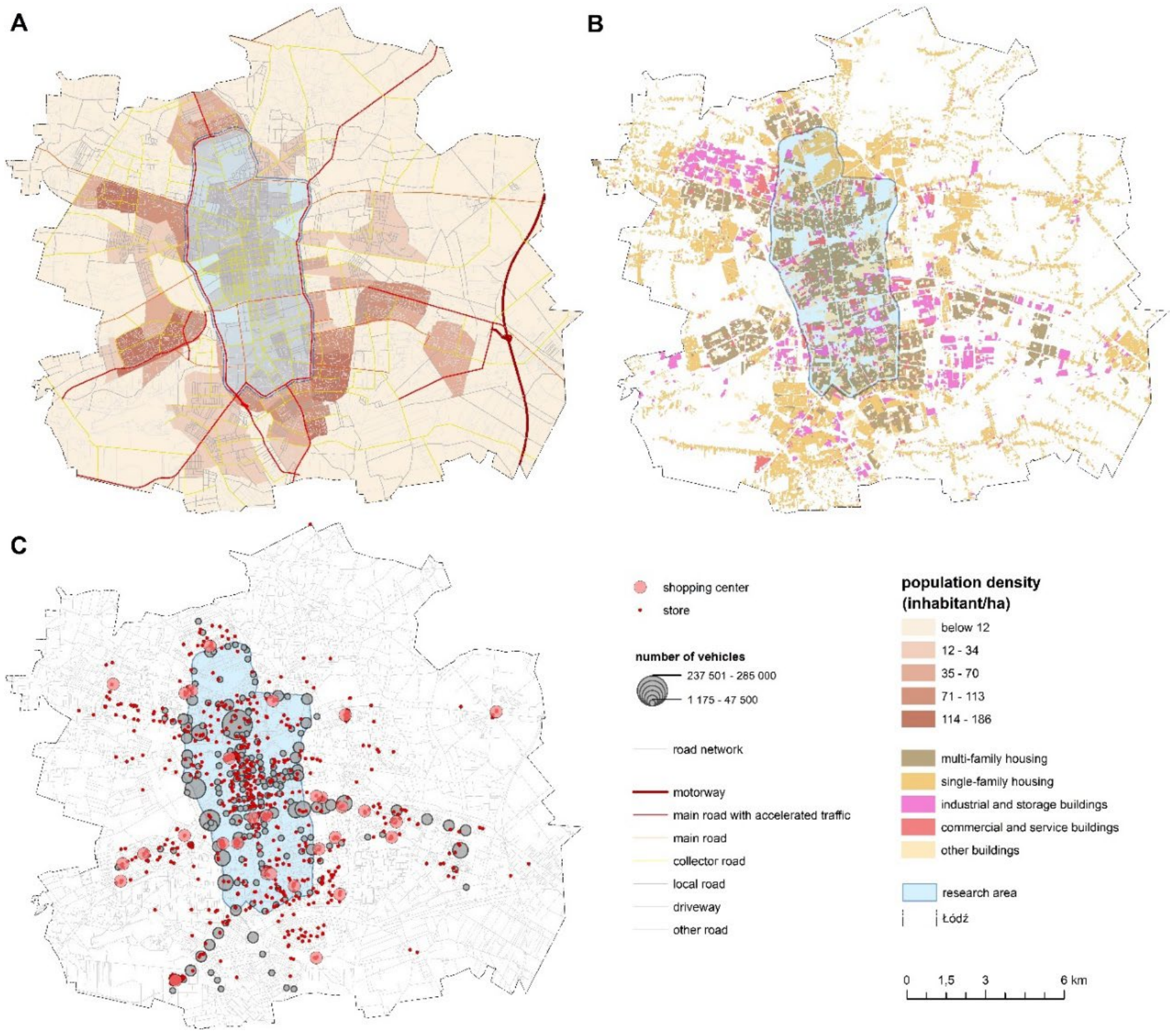

Fig. 1. (A) Location of the researched area against spatial differentiation of population density and the city's road network, (B) types of built-up areas, and (C) distribution of retail facilities and average daily traffic of vehicles in 2019.

For ITS to function effectively, the road network is equipped with certain devices. Examples include measurement sensors, cameras, weather stations, variable message signs, communication networks.

Based on the ITS data, the average number of vehicles for the study area amounted to almost $76 \%$ of the city's total number of vehicles. As a result of this private car use, transport-related issues escalate, especially in the central part of Lodz, where the highest transport-induced air pollution is recorded. The 2020 report compiled by the Regional Department of Environment Monitoring (RDEM) in Lodz shows that excessive $\mathrm{PM}_{2.5}$ concentrations stem, inter alia, from transport emissions, which is particularly noticeable along highly congested roads (including those in the city center). The analysis of the average annual $\mathrm{PM}_{2.5}$ intensity [ $\mu \mathrm{g} \mathrm{m}^{-3}$ ] between 2015 and 2019 reveals that all three air quality monitoring stations in Lodz (two of which are located within the researched area - Legionow 1 and Gdanska 16) recorded results slightly exceeding the acceptable standards of health protection recommended by the WHO. The highest readings were recorded in 2017, at the station on Legionow Street (located almost in the very center of the analyzed 
area), where the average value of $\mathrm{PM}_{2.5}$ concentration in this study is $32.5\left[\mu \mathrm{g} \mathrm{m}^{-3}\right.$ ]. In 2019 , the intensity dropped by nearly 10 p.p. to 22.5 [ $\mathrm{g} \mathrm{g} \mathrm{m}^{-3}$ ] (RDEM in Lodz 2020). However, the guideline value of $\mathrm{PM}_{2.5}$ concentration should not exceed $5 \mu \mathrm{g} \mathrm{m}^{-3}$ on an annual average basis (WHO, 2021).

Since most pollution is caused by linear emissions, it is also worth analyzing the city's private cars. According to the Polish Central Statistical Office in 2019, the majority of passenger cars registered in Lodz had an engine with a displacement ranging from 1,400 to 1,999 cc and a gross vehicle weight between 1,400 and 1,649 kg. As for commercial vehicles, over half were LCVs with a maximum payload of $999 \mathrm{~kg}$. Another vital aspect for the analysis of air quality and transport-related pollution is vehicle age and fuel type used. Unfortunately, the Polish Central Statistical Office shows no specific data on the actual number of vehicles in the city, only information on the vehicles registered there. The available data shows that in 2019, the majority of vehicles registered in Lodz were between 16 and 20 years old, and that more than a half $(53.2 \%)$ ran on petrol.

Information on traffic volumes throughout the road network was retrieved from the Regional Traffic Control System in Lodz, a derivative of the SCATS (Sydney Coordinated Adaptive Traffic System). SCATS monitors traffic within the network, controls traffic lights on the basis of traffic volumes and congestion, and, following specifically determined criteria, imposes a control and coordination strategy to manage neighboring intersections. Traffic density and load - input data indispensable for SCATS - are measured by detectors (inductive loops) installed a short distance ahead of the limit line (Li et al., 2014) on each lane. On the basis of this data it is possible to capture traffic volumes within the network (Kowalski and Wiśniewski, 2017) and their directional structure (Borowska-Stefańska et al., 2021b), which is particularly valuable for both macro- (Hueper et al., 2009) and intermediate-scale analyzes (Bieker et al., 2015; Borowska-Stefańska et al., 2021a). The aforementioned detectors (inductive-loop traffic detectors) are a solution that is most commonly applied to measure road traffic parameters, since they offer good performance regardless of weather conditions (Gajda et al., 2001). They utilize the phenomenon of eddy currents, i.e., a change in the magnetic field is caused by a metal object and this data is then registered (Burnos et al., 2011). Despite their advantages, detectors cannot be claimed to be completely faultless and error-free, which may result in inaccurate measurements of the number of vehicles (Li et al., 2014). Therefore, results must be verified - all extreme values and those predefined by the system as erroneous must be removed. SCATS data does not provide information on trip motivators, starting points and destinations that road users have in mind, it only presents the load of the network that reflects the journeys made by users at a given time. In consequence, SCATS-based studies are of a general, holistic nature - they analyze all trips without specifying individual dimensions of the traffic. However, there are attempts in the scientific literature to use these data to explore traffic issues in greater depth. An example of this is the modelling of movement using detector data with SUMO using the DFROUTER tool, which was used to generate the O-D matrix (Zambrano et al., 2016).

The data used in our study was retrieved from the SCATS system and contains measurements conducted at 15-minute intervals by each detector located prior to the limit line on lanes for cars (no tram traffic included) within the researched area for a period of two separate months (March 2019 and March 2020). All duplicated measurements from sensors installed ahead of the limit line were ignored. The said detectors amount to $100 \%$ of this type within the analyzed area and $78.2 \%$ of all such sensors in Lodz (Fig. 2). Next, the data was aggregated to hourly measurements, with the average value for each hour calculated for each day of the week. In consequence, it was then possible (owing to detailed detector geolocation) to further aggregate the data. At this stage, any measurements incompatible on a year-to-year basis (e.g., due to modernization of the transport network or expansion of the SCATS system) were eradicated. As a result, a database was created. The database contained spatial information on the location of measurements within the transport network and average number of vehicles recorded within the network at individual hours for each day of the week in March 2019 and March 2020.

\subsection{Flow Estimation Model}

Reviewing the literature shows that several methods have been used in the previous studies for estimation of the traffic flow in the road networks (e.g., neural networks (Fu et al., 2017), Thiessen polygons (Gómez et al., 2018), spatial autoregressive moving average (Sun et al., 2018), 


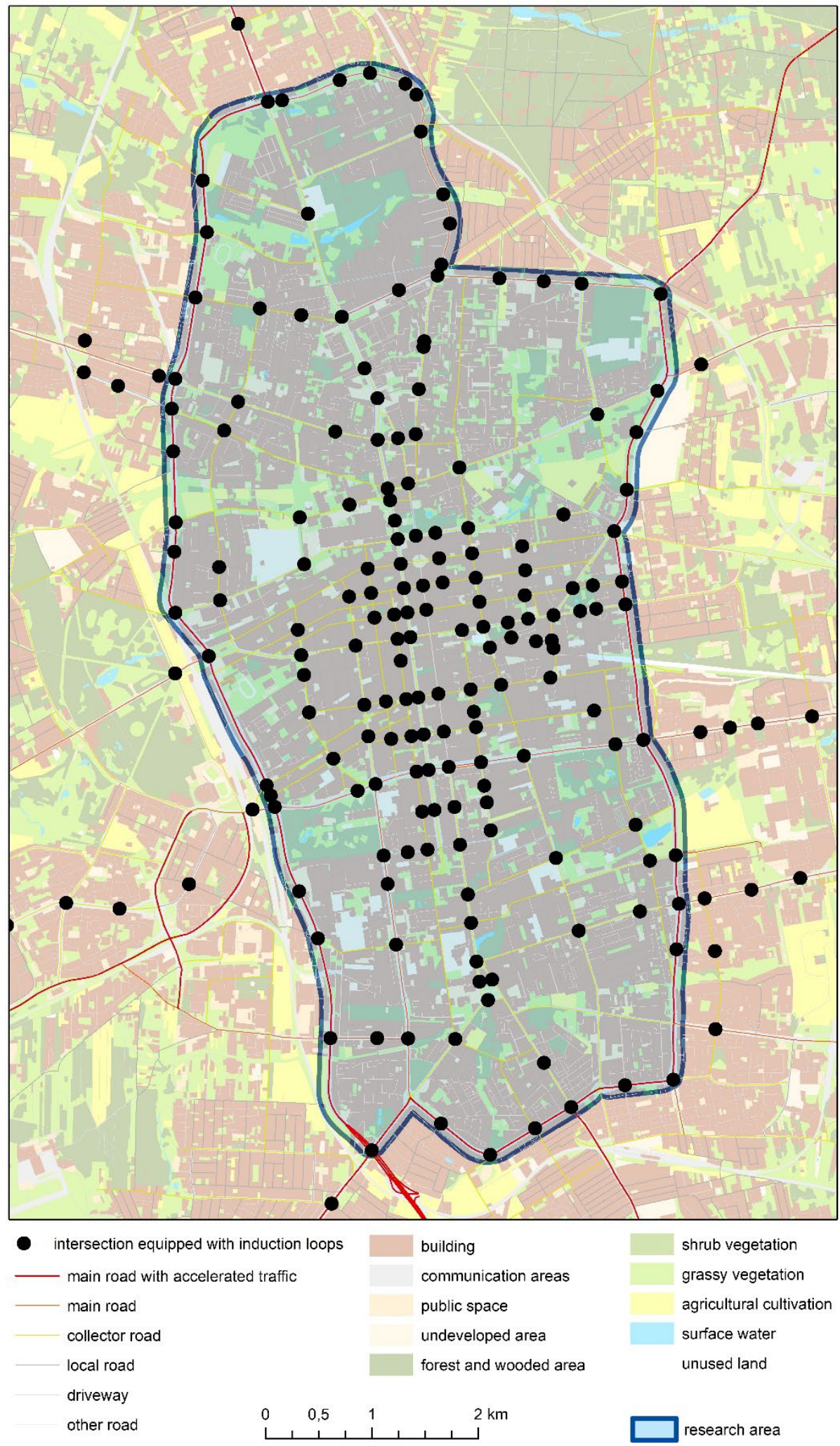

Fig. 2. Distribution of inductive loops in the researched area and its immediate vicinity.

geographically weighted regression (Song et al., 2018), and Kriging models (Selby and Kockelman, 2011; Selby and Kockelman, 2013; Shen and Hadi, 2013; Shamo et al., 2015; Yang et al., 2018; Pinto et al., 2020)). Studies depicted that accuracy of Kriging methods taking multiple adapted weight parameters and correlated errors into account is more satisfactory for flow estimation 
than the regression models which regard single parameter and treat errors as white noise (Van Beers and Kleijnen, 2004). Neural networks and Thiessen polygons also have some shortcomings. The former neglects error distribution and parameter stability (Fu et al., 2017), and the latter allocates the same flow values to the segments in a polygon (Gómez et al., 2018). In addition, regression-based techniques lack casual relationships and require a great amount of input data that increases analysis costs considerably (Khan et al., 2018). However, Kriging models are suitable and reasonable choices for traffic-related applications (Zou et al., 2012) because they are compatible with limited observations (Aultman-Hall and Du, 2006) and reliable for analyzing spatial data (Wang and Kockelman, 2009).

It should be noted that the above-mentioned predictive models cannot completely replace the real traffic counting procedure. But, they have a great potential to reduce data collection cost and time and to assist analysts to conduct their studies by providing representative flows for the networks (Pinto et al., 2020) when real values are not available. Regarding the advantages of Kriging methods over the other predictive ones for spatial analysis and their acceptable results for modeling street networks (Kim et al., 2016; Klatko et al., 2017; Pinto et al., 2020; Shukla et al., 2020), this model is described in the next part of the text.

Kriging is a distance-dependent method in which the model outputs rely on the way the environmental distances are represented throughout the process. Mainly two distance types are considered for representation of the networks in the Kriging process, which are, Euclidean and network-based distances. Although some pieces of research indicated that network-based distances performed better than the Euclidean ones (Zou et al., 2012), some other works found that using network-based distances had no significant impacts on improving the results compared to the Euclidean forms (Selby and Kockelman, 2011). This way, it can be said that the accuracy of the methods for modeling the road networks might be varied case by case, and to decide which one is more suitable for a study area, experimental and validation analysis is required. Also, it should be noted that there is a wide range of Kriging methods for estimating spatial phenomena from Simple, Ordinary, and Universal to Bayesian models. To select among these algorithms, autocorrelation and trend of the spatial data should be examined. Based on these features, the Kriging method compatible with the structure of the spatial data in a certain area can be identified. To do so, first, the related network to the study area is created through the below process proposed by Zou et al. (2012), and the flow values are assigned to the points in the transformed space.

a) Midpoint of each link in the study area is created. It is assumed that each midpoint is the source of flow in the street network, which is an acceptable assumption in geographical sciences and used by the previous works (Selby and Kockelman, 2013; Pinto et al., 2020).

b) Network-based distance of the midpoints along with the inductive loops is measured using Network Analysis Tool and OD cost matrix in the ArcGIS environment.

c) All points are transformed to the isometric space which results in new coordinates of the points keeping distances computed in Step a. For performing the transformation process, firstly, network-based distances are mapped into a high-dimensional subspace through Eq. (1) where $d_{i j}$ is the network distance between points $i$ and $j$.

$$
b_{i j}=\frac{1}{2}\left(-d_{i j}^{2}+\frac{1}{n} \sum_{j=1}^{n} d_{i j}^{2}+\frac{1}{n} \sum_{i=1}^{n} d_{i j}^{2}-\frac{1}{n^{2}} \sum_{i=1}^{n} \sum_{j=1}^{n} d_{i j}^{2}\right)
$$

Secondly, eigenvalues of matrix $B=\left\{b_{i j}\right\}_{n \times n}$ denoted by $\lambda_{1} \geq \lambda_{2} \geq \ldots \lambda_{n}$ is generated, and the $k$ greatest values represented by $\lambda_{1} \geq \lambda_{2} \geq \ldots \lambda_{k}>0$ are selected, and their normalized eigenvectors are computed $\boldsymbol{\Gamma}=\left(e_{1}, e_{2}, \ldots, e_{k}\right)$. Thirdly, new coordinates in the $k$-dimensional subspace is calculated by $\Gamma \sqrt{\Lambda}$ where $\Lambda=\operatorname{diag}\left(\lambda_{1}, \lambda_{2}, \ldots, \lambda_{k}\right)$. This step is executed in MATLAB environment.

d) Accuracy of the constructed network in the previous step depends on the choice of parameter $k$. Therefore, the validity of the transformed coordinates needs to be assessed. Two metrics can be regarded for validity analysis. First, the ratio of the sum of the first $k$ eigenvalues to the sum of the entire eigenvalues $K=\sum_{i=1}^{k} \lambda_{i} / \sum_{i=1}^{n}\left|\lambda_{i}\right|$ is obtained, and the 
value of this proportion is calculated for different values of $k$ (Mardia et al., 1979). At a certain point, value of $K$ does not improve significantly, and the optimum $k$ can be found. Second, to evaluate the fitting quality, STRESS indicator introduced by (Kruskal and Wish, 1978 ) is quantified (Eq. (2)). This indicator has three cut-off points (i.e., $2.5 \%, 5 \%$, and $10 \%$ ). If STRESS is greater than 0 and smaller than or equal to $2.5 \%$, the quality of the fitting is very good. If STRESS is greater than $2.5 \%$ and smaller than or equal to $5 \%$, the fitting is good. If STRESS is greater than $5 \%$ and smaller than or equal to $10 \%$, the fitting is fair. Otherwise, the fitting quality is bad.

$$
\text { STRESS }=\sqrt{\sum_{i} \sum_{j}\left(d_{i j}^{o b s}-d_{i j}^{e s t}\right) / \sum_{i} \sum_{j}\left(d_{i j}^{e s t}\right)^{2}}
$$

e) If the transformation process is valid, existing flow values will be joined to the points generated in Step $d$, and these new features will be considered for further analysis.

Second, having the distribution of points in the Euclidian and Network-based spaces, the spatial structure of data is checked in terms of autocorrelation and trend. Autocorrelation can be analyzed by measuring Moran's I, and this index can be statistically tested to examine whether the calculated value is significant. Moran's I is computed through Eq. (3), where $I$ is Moran's I, $n$ is the number of spatial units in a study area, $w_{i j}$ is spatial weight of point $i$ and $j, \bar{X}$ is the mean of spatial values, and $x_{i}$ and $x_{j}$ are values of point $\mathrm{i}$ and $\mathrm{j}$, respectively. $I$ varies between -1 and +1 , and the more the value of $l$ is closer to +1 , the more the data is autocorrelated and has the clustered pattern. The null hypothesis for testing Moran's I indicates the lack of autocorrelation, and the alternative hypothesis states the existence of autocorrelation. If $p$-value is very small (i.e., smaller than 0.05 for confidence interval 0.95 or smaller than 0.1 for confidence interval 0.90), the existence of autocorrelation is confirmed, which means that the null hypothesis will be rejected and the alternative one will be accepted.

$$
I=\frac{n \sum_{i=1}^{n} \sum_{j=1}^{n}\left(w_{i j} \times\left(x_{i}-\bar{X}\right) \times\left(x_{j}-\bar{X}\right)\right)}{\left(\sum_{i=1}^{n} \sum_{i=1}^{n} w_{i j}\right) \times\left(\sum_{i=1}^{n}\left(x_{i}-\bar{X}\right)^{2}\right)}
$$

Trend is a systematic change in data across an area and can be detected by drawing the trend graph that depicts the analytical pattern of the variation in a given dataset. After determining the proper Kriging method for the Euclidean and Network-based spaces, cross-validation is applied to identify which space representation performs better for simulation of the study area with a smaller amount of errors since there is a trade-off between the computational burden and accuracy level for each type of the space representations. For instance, the computational burden of the Network-based representation is much greater than Euclidean one, but it does not guarantee whether the Network-based predictions are meaningfully better than the Euclidean model. Thereby, implementing cross-validation is a necessary task before running the entire method and obtaining the ultimate outputs. Application of these tests together with the calibration and application processes are explained in Section 3.

\subsection{Emission Model}

There are different approaches for modeling emissions having traffic flows in the networks. For example, Liu et al. (2019) developed a model based on travel distance and emission variables for measuring the level of pollution dispersed by taxis in Hangzhou, China. Wang et al. (2020b) proposed an equation incorporating travel time, and emission and penetration rates in the dispersion calculation process. Fu et al. (2020) elaborated an emission model on the ground of computational fluid dynamics concepts working at the fine scales. Phillips et al. (2021) applied pollution source strength across the road types, background parameters, and dispersion patterns as the main factors and combined them using decay functions.

To select a general modeling structure along with supporting notion and spatial resolution of 
the emission model, three factors need to be considered. The first factor is data availability, the second is modeling purpose(s), and the third is the expected usage of the results. Regarding existing data in the study area (described in Section 2.1) and the aim of this paper which is to analyze the general pattern of the pollution dispersion, an equation that concentrates on the main transportation-related variables is delineated for the passenger cars. This equation inspired by frameworks offered by Pinto et al. (2020) and Ntziachristos and Samaras (2020) is represented below, where $P C E_{i}^{j}$ is the emission value of pollutant $j$ generated by passenger cars along link $i$ in the network, $V_{i}$ is the flow in link $i, L_{i}$ is the length of link $i$, and $P_{j}$ is the amount of emitted pollutant $j$ per length (i.e., kilometer).

$$
P C E_{i}^{j}=V_{i} \times L_{i} \times P_{j}
$$

Different pollutants have been taken into account in the existing literature (i.e., $\mathrm{NO}$ and $\mathrm{NO}_{2}$ (Ferreira et al., 2000), $\mathrm{CO}$ and $\mathrm{CO}_{2}$ (MacNaughton et al., 2014), $\mathrm{O}_{3}$ (Bell, 2006), BC (Wang and Kockelman, 2009), BS (Brunekreef et al., 2009), $\mathrm{SO}_{2}$ (Son et al., 2010), UFP (Zwack et al., 2011; Kingham et al., 2013), and VOC (Bigazzi and Figliozzi, 2015)). Among them, fine particulate matter $\left(\mathrm{PM}_{2.5}\right)$ is a pollutant that brings diverse and adverse health outcomes to people living in human settlements (Kheirbek et al., 2016). This pollutant has a more destructive effect on the human respiratory system than the gaseous composites like $\mathrm{CO}_{2}$ and $\mathrm{NO}_{2}$ (Miri et al., 2016). In addition, reports showed that $\mathrm{PM}_{2.5}$ causes 3.5 million of deaths from lung cancer and more than 220 thousand from cardio-vascular diseases annually (Hao et al., 2012; Krishnan et al., 2012). Additionally, the importance of evaluating this pollutant emitted from transportation systems has been explicitly emphasized by the previous studies (e.g., Zuurbier et al. (2010); Apte et al. (2011); Quiros et al. (2013); Weichenthal et al. (2015)). Thus, $\mathrm{PM}_{2.5}$ is regarded as the contributing pollutant in the emission model. It should be noted that so long as the required data be available and the modeling process be valid, the application of the given framework will not be limited to $\mathrm{PM}_{2.5}$, and it can be utilized for assessing other pollutant types spatially and temporally. Another point is that $P_{j}$ can be disaggregated based on several factors such as vehicle type, fuel type, vehicle weight, local observations, and so on. But, when only aggregated and low-resolution data be at hand, small-scale emission rates cannot be directly used in the calculations. One way to address this issue is to consider the conditions of a certain study area and to define a logical scenario compatible with the available data. A plausible scenario that provides perspectives for planning and has been followed by several studies (e.g., Iqbal et al. (2020)) is to model higher concentration values called the worst-case scenario. In this scenario, measurements are conducted based on the highest level of pollution generation rate. As large and heavy vehicles are banned to enter the study area and noting the fact that the dominant transportation mode is passenger car (about $88 \%$ ) with petrol fuel (about 60\%), considering the $\mathrm{PM}_{2.5}$ emission rate equal to $0.0022 \mathrm{~g} \mathrm{~km}^{-1}$ would be admissible for the worst-case scenario according to (Ntziachristos and Samaras, 2020).

\subsection{Integration of Flow and Emission Models}

After developing both flow and emission models, the outputs can be obtained through an integrated structure illustrated in Fig. 3. First, traffic flow for each link in the network is estimated using a proper method identified by comparing and analyzing Kriging methods and data structures in the Euclidean and isometric transformed spaces. Second, based on parameters such as characteristics of the study area, and the existing data and literature, the emission model containing the flow factor is articulated. Third, outputs of the first and second steps are combined and emission generated along each link in the network is measured. Fourth, to produce the spatiotemporal pattern of pollution dispersion, the emission surface is interpolated through Kriging method utilized by other studies (e.g., Kumar et al. (2020); Pinto et al. (2020)).

\section{RESULTS AND DISCUSSON}

\subsection{Network Representation and Kriging Model Selection}

For creating the isometric transformed network, the method represented in Section 2.2 was 

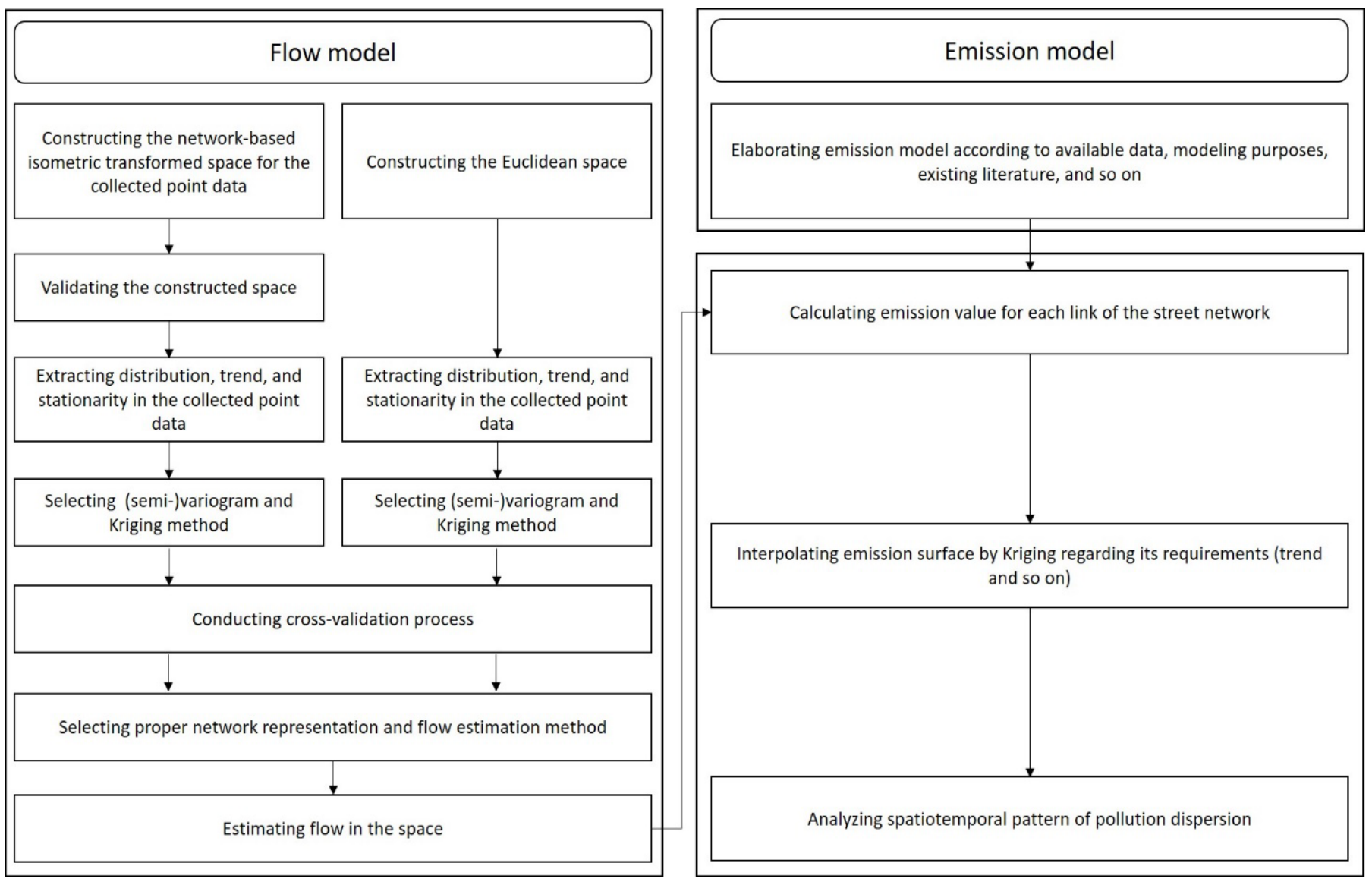

Fig. 3. Integration framework of flow and emission models.

applied to the points with the collected data. As the choice of dimensionality is the key component in the network construction, parameter $K$ was measured for different values of dimensions denoted by $k$. Fig. 4 depicts that $K$ had a sharp rise from dimensions 1 to 2 but its growing tendency slowed down for the higher dimensions. Furthermore, comparing semi-variograms for the dimensions did not show significant improvement by the increase in the number of dimensions.

To show the accuracy of the generated spaces, STRESS indicator was calculated through Eq. (2). For $k=2$, STRESS value was 0.0036 that confirmed a very good fitting result. Putting all of these outputs together, it could be concluded that the increase in the dimensionality parameter which imposes more computational burden, did not lead to better results in the study area. This way, $k$ $=2$ is an acceptable choice for the development of the transformed space, and this value is used in other steps of the analysis.

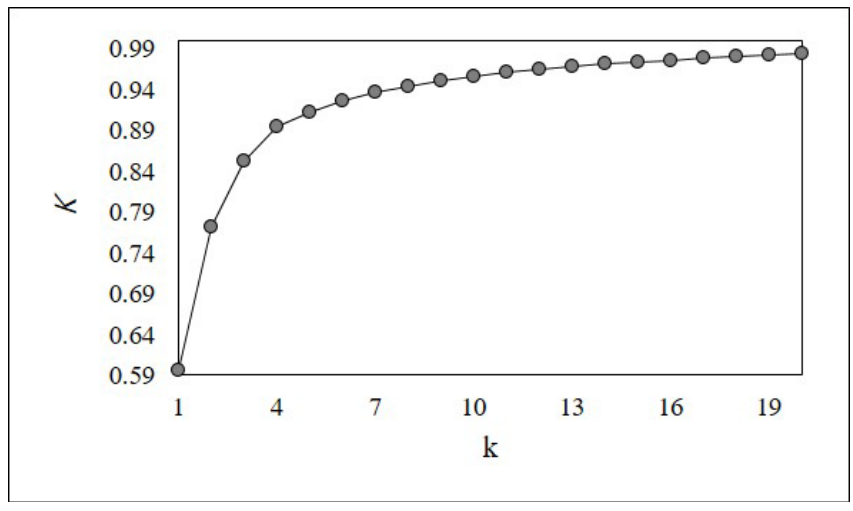

Fig. 4. $K$ value plotted versus dimensionality values. 
Table 1. t-test results for RMSE and ASE values in the transformed and Euclidean spaces in March 2019 and 2020.

\begin{tabular}{lll}
\hline & t-value & Sig (2-tailed) \\
\hline RMSE 2019 & -0.017 & 0.987 \\
RMSE 2020 & -0.057 & 0.955 \\
ASE 2019 & 0.518 & 0.607 \\
ASE 2020 & 1.452 & 0.153 \\
\hline
\end{tabular}

After creating the transformed space and having the Euclidean space, the trend and autocorrelation in the spatial data were checked for these configurations based on the collected data. Figs. S1 and S2 (given in Supplemental material) display the trend of spatial data in the transformed and Euclidean spaces in March 2019 (before pandemic) and 2020 (after pandemic), respectively. These diagrams confirm the existence of the trend in the hourly spatial data in both spaces and time spans.

Table S1 (given in Supplemental material) illustrates autocorrelation in the spatial data in the transformed and Euclidean spaces. This table, which includes Moran's I along with the results of the statistical significance analysis, shows that there is autocorrelation in the hourly spatial data in both spaces in March 2019 and 2020. Owing to the trend and stationarity in the spatial data structure, Universal Kriging with exponential function which is analytically able to present underlying patterns of stationary data with trends better than the other common Kriging models was utilized for the flow estimation. But, as the results can be acquired from the transformed and Euclidean spaces, before estimating flows for the entire network and constructing the ultimate transformed space that is computationally complex, the application of either space should be decided.

To do so, cross-validation was implemented on the gathered data in both spaces, and Root Mean Square Error (RMSE) together with Average Standard Error (ASE) were computed for the results. For evaluating meaningfulness of the statistical difference between the error values and the impact of the transformed space on the reduction of the modeling errors compared to the Euclidean one, t-test was performed on the obtained RMSEs and ASEs for March 2019 and 2020 separately. Table 1 shows the results and implies that the difference between the errors is not significant. Thus, considering the computational difficulty of calculations in the transformed space along with the experiments which confirmed that isometric transformation did not lead to lower errors in the study area, the Euclidean space was executed for further estimations.

\section{2 $\mathrm{PM}_{2.5}$ Emission Estimation and Distribution Analysis}

After flow calculation, emission along each link was calculated through Eq. (4), and the spatiotemporal distribution of $\mathrm{PM}_{2.5}$ across the study area was generated using Kriging method regarding trend and stationarity in the pollution data structure at hourly intervals in March 2019 and 2020. Fig. 5 portrays the hourly distribution of the normalized pollution values emitted in the study area. It shows that the level of emissions before and after the COVID-19 pandemic was considerably different and carrying out the restrictions had a substantial impact on the traffic flow generated by the passenger cars and consequently on the production of the emissions.

Fig. 6 depicts the spatial and temporal patterns of dispersion in four representative and distinctive examples (i.e., peak and off-peak times) before and after the pandemic. It can be seen that before the pandemic, pollution was highly concentrated around the edge and in the heart of the city. The level of concentration gradually went down after the peak hours and went up when the time moved toward such time slots. This effect could be explained by considering the condition that before lockdown, people tend to access facilities in the study area, and in the absence of the restrictive policies, generated flows spilled inward and outward of the area under consideration. After introducing bans and prohibitions including activity and travel limitations, the load of pollution became substantially lower all over the study area specifically in the central parts. Furthermore, several scattered pollution hotspots could still be identified around the boundary of the central area of the city of Lodz. However, the intensity of these places and their impact area were not as high as the states before the pandemic in March 2020. The reason is that after 

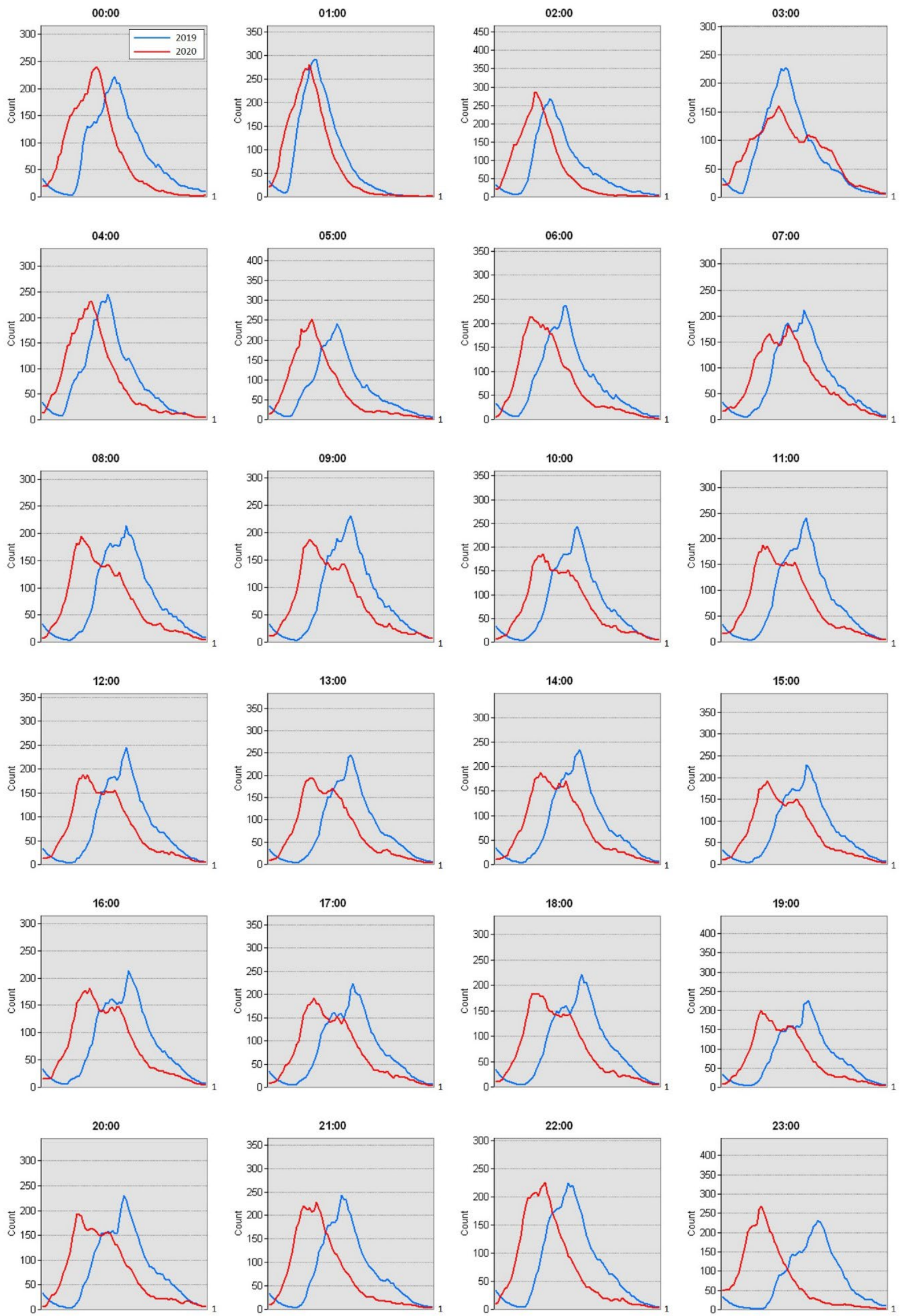

Fig. 5. Normalized hourly pollution distribution in Mach 2019 (blue line) and 2020 (red line). 
2019
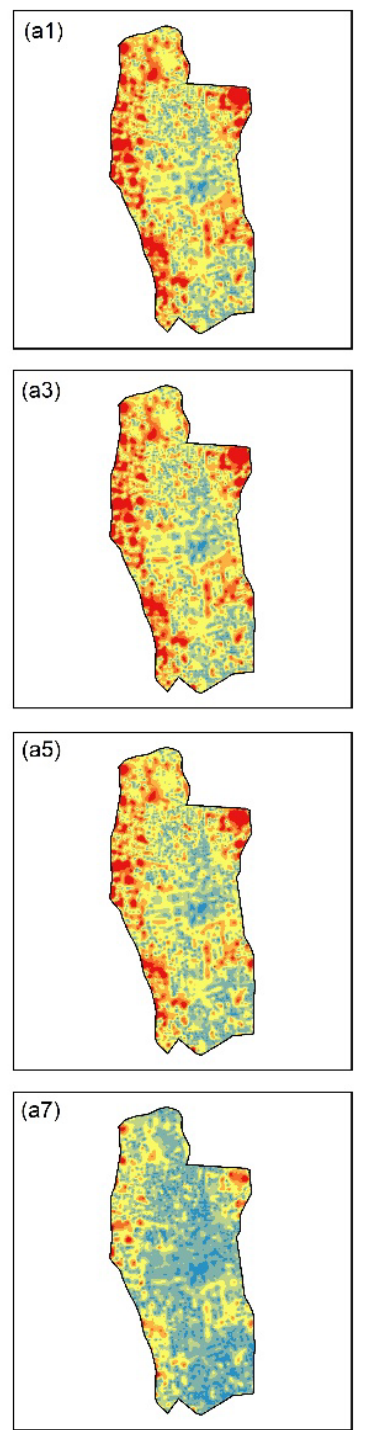

2020
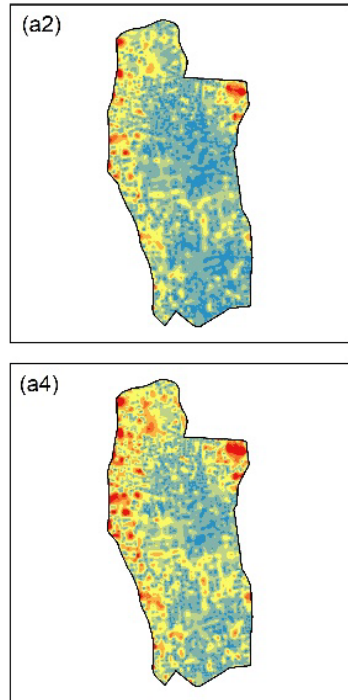

(a6)

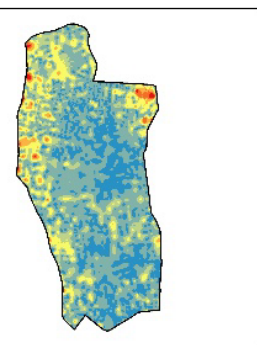

(a8)

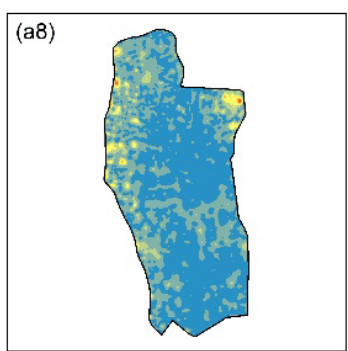

2019
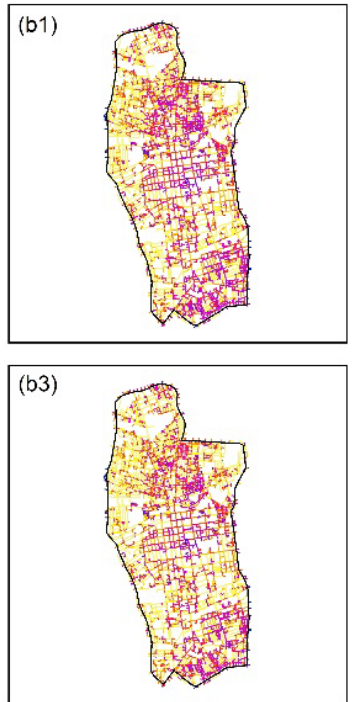

(b5)
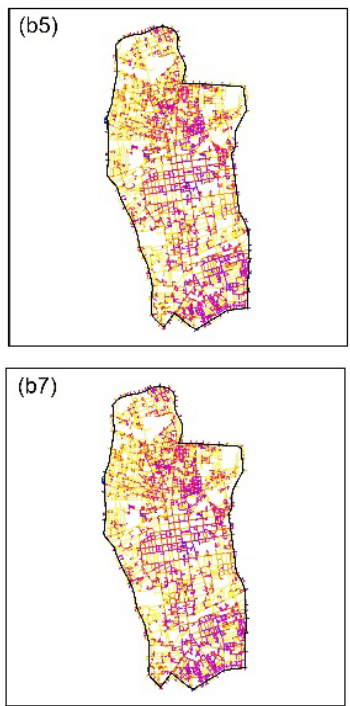

2020
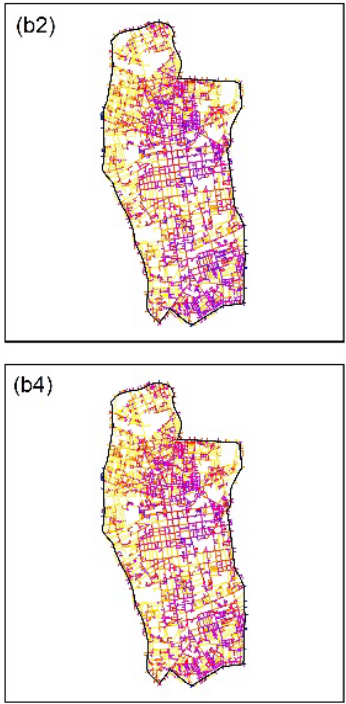

(b6)
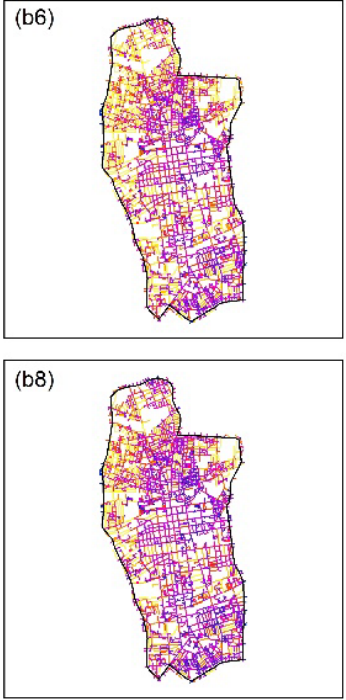

08:00

$14: 00$

18:00

20:00

(a1)-(a8): Pollution dispersion surface in March 2019 and 2020

(b1)-(b8): Pollution dispersion pattern at the street level in March 2019 and 2020

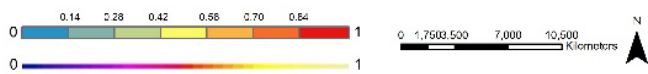

Fig. 6. Spatial pollution emission in March 2019 and 2020 (normalized values). The first set of plots (a1-a8) illustrates dispersion surface in the study area, and the second (b1-b8) shows dispersion at the street level.

implementation of the lockdown measures, some activities were closed and movement between different places was faced with difficulties. Therefore, traffic generation was decreased, and owing to the movement barriers, the volume of attracted and produced flows fell down. Consequently, emission values were reduced and impact areas affected by the pollutants became smaller. Besides, it could be said that despite the pollution and flow reduction in March 2020 compared to March 2019, due to the importance of doing some necessary activities or working in sectors delivering critical services even in the lockdown period, usage of the passenger cars was continued.

Moreover, apart from the general dispersion pattern described above, the pollution density of some spots was the same before and after the pandemic. These places are mainly located in the east and north-west part of the study area (Fig. 7). This way, such locations could be regarded as the high prioritized zones for preparing spatial policies such as land-use rearrangement or traffic pricing programs. Thus, another potential that can be taken for the application of the outputs in practice is the creation of pollution risk and intervention maps that could assist policy- and decision-makers in the establishment of future development strategies. 


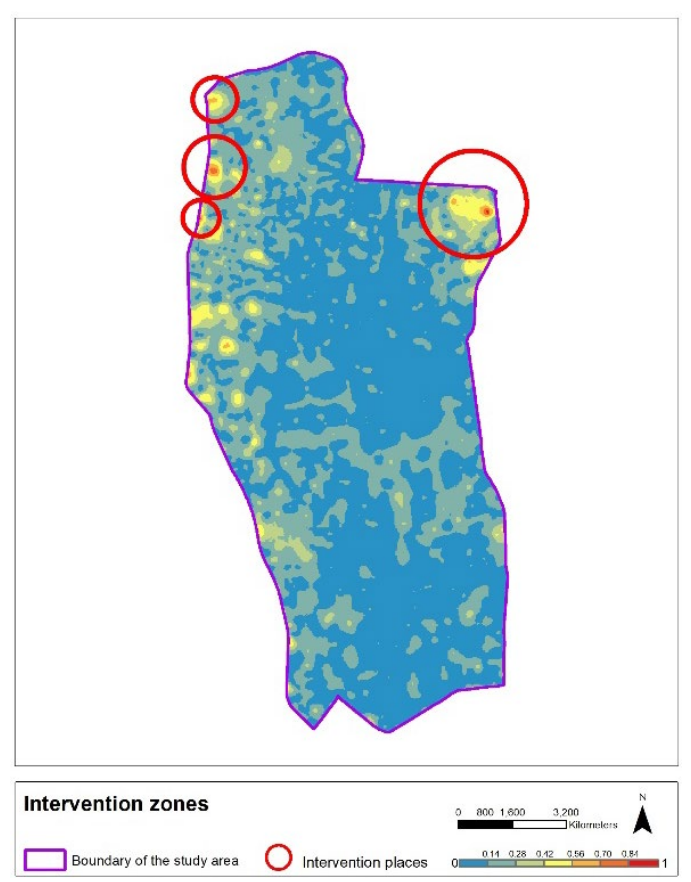

Fig. 7. Interventions zones. Hotspots (marked by the red circles) have been extracted from the representative pollution distribution maps by finding common locations with the highest pollution levels.

\subsection{Research Limitations and Future Works}

The first limitation of the model elaborated in this article is that although the applied method incorporates temporal dimension, it is static and does not represent dynamics underlying the pollution emission phenomenon. For example, in the utilized model, dispersion of the pollutants is modeled at a point in time, and the circulation of traffic flow inside and outside of the area under consideration is not taken into account between the pre-determined time steps (e.g., only dispersion at 00:00 and 01:00 is obtained but states in the middle of these times are not calculated). Although disregarding dynamic movement might deviate the results, outputs are still plausible following the previous studies (e.g., Pinto et al. (2020)) and the compatibility of the results with the general body of knowledge of the geographical analysis.

The second limitation is related to the factors affecting pollution dispersion. For more realistic outputs, variables such as wind direction, street channel, velocity, and acceleration can be considered in the modeling structure. However, to treat these factors, high-resolution data and more complex processes are required. Albeit the utilized framework in this article is admissible and supported by the existing literature (e.g., Kumar et al. (2020); Ntziachristos and Samaras (2020); Pinto et al. (2020)) and the available data, putting the indicated constructs in the modeling structure can be pursued by the future studies.

The third restriction pertains to the travel modes other than the passenger cars. Generally, in the transportation networks, different vehicles with different characteristics (e.g., mass, size, fuel consumption, and so forth) are involved, which can affect the amount of pollution generation. Although this item has not had a great impact on the study area represented in this research (as stated in Section 2.3), extending the proposed model to other modes can be regarded for future works.

Further to the above-mentioned limitations, other extensions can be taken into account for future studies. First, this article only examined the emission of $\mathrm{PM}_{2.5}$. Therefore, the application of the model for finding the dispersion pattern of the other pollutants can be followed by another research. Also, in addition to the analysis and experiments presented in this article and the points brought up by the relevant studies (e.g., Wang and Kockelman (2009); Selby and Kockelman (2011); Selby and Kockelman (2013); Pinto et al. (2020)) which justify using spatial analysis techniques for the flow and emission estimation, in the case of data availability, testing other predictive 
methods (e.g., meteorological and remote sensing ones) and comparing their outputs with the Kriging model can be regarded as another noteworthy extension to this research.

\section{CONCLUSIONS}

The purpose of the article was to determine (using Lodz as an example) the impact of the COVID-19 pandemic on $\mathrm{PM}_{2.5}$ emissions for urban transport networks. Data from inductive loops and the Kriging method were applied to accomplish the research objective. The impact (assessed by amounts of pollution) was determined exclusively on the basis of data on the numbers of passenger cars within the road network. The conducted analysis showed that the traffic restrictions introduced during the COVID-19 pandemic contributed to the improvement of air quality in Lodz.

Numerous studies have shown that air pollution is strictly correlated with transport, and $\mathrm{PM}_{2.5}$ emissions especially pose a particularly dire threat to life and health, primarily in populous urban areas. Levels of pollutant emissions before and during the pandemic fluctuated greatly. Prior to the pandemic, $\mathrm{PM}_{2.5}$ pollution was highly concentrated in the center and peripheral parts of the analyzed area. It would gradually drop outside rush hours and grow at peak hours. Upon the lockdown (including traffic restrictions due to the COVID-19 pandemic), the pollution load throughout the whole area, and across its central parts in particular, decreased dramatically. Not only did the restrictions lower the amount of car-induced $\mathrm{PM}_{2.5}$ emissions, but they also made the impact zones noticeably smaller. Therefore, the study clearly shows that restrictions in car use can play a crucial role in the reduction of air pollution in large cities, which, additionally, would help accomplish objectives of sustainable development. Although the outbreak of the COVID-19 pandemic clearly poses a serious threat to life and health, it has had an exceptionally positive impact on the natural environment, becoming an unconventional mechanism for its restoration. The implementation of pandemic-related traffic restrictions has made it possible to conduct a peculiar 'experiment' to assess the impact of changes in travel behavior on air pollutant emissions - an important issue not only in the analyzed city (Lodz), but many other large agglomerations with densely populated and highly developed city centers facing transport-related problems.

All actions taken to restore the natural environment are vital not only for us at this time, but, above all, for future generations. Importantly, the analyses described in this paper offer a practical dimension - for instance, the results and the model itself can be used to create pollution maps, which may be extremely useful for decision-makers responsible for transport policies wishing to follow the principles of sustainable development. What is more, those studies that have assessed air pollution and its decrease following the introduced car use restrictions will be very important in determining the durability of the effect once the COVID-19 pandemic restrictions are lifted fully. The results will enable the formulation of new guidelines and recommendations for transport policies (especially in urban areas) compiled to accomplish objectives of sustainable development, including improvement of air quality in cities. A new transport policy on traffic would help create low-emission zones in metropolises, which is essential in densely populated urban areas (which in Lodz refers, in particular, to the city center). Research of this kind also facilitates a better understanding of the impact car traffic restrictions have on air quality.

\section{ACKNOWLEDGMENTS}

The article was written in connection with the project no. 2019/35/D/HS4/00697 funded by the National Science Center in Poland.

The authors would like to thank the Editor-In-Chief, Professor Neng-Huei (George) Lin, and the Editor, Dr. Stephen Griffith, for providing a very smooth and efficient review process. Also, the authors are thankful to the anonymous reviewers for their insightful and constructive comments.

\section{SUPPLEMENTARY MATERIAL}

Supplementary material for this article can be found in the online version at https://doi. org/10.4209/aaqr.210313 


\section{REFERENCES}

Abdul-Wahab, S.A., Fadlallah, S.O. (2014). A study of the effects of vehicle emissions on the atmosphere of Sultan Qaboos University in Oman. Atmos. Environ. 98, 158-167. https://doi.org/10.1016/j.atmosenv.2014.08.049

Agudelo-Castañeda, D., Teixeira, E., Rolim, S., Pereira, F., Wiegand, F. (2013). Measurement of particle number and related pollutant concentrations in an urban area in South Brazil. Atmos. Environ. 70, 254-262. https://doi.org/10.1016/j.atmosenv.2013.01.029

Apte, J.S., Kirchstetter, T.W., Reich, A.H., Deshpande, S.J., Kaushik, G., Chel, A., Marshall, J.D. Nazaroff, W.W. (2011). Concentrations of fine, ultrafine, and black carbon particles in auto rickshaws in New Delhi, India. Atmos. Environ. 45, 4470-4480. https://doi.org/10.1016/j. atmosenv.2011.05.028

Aultman-Hall, L., Du, J. (2006). Using spatial analysis to estimate link travel times on local roads.

Bell, M.L. (2006). The use of ambient air quality modeling to estimate individual and population exposure for human health research: A case study of ozone in the Northern Georgia Region of the United States. Environ. Int. 32, 586-593. https://doi.org/10.1016/j.envint.2006.01.005

Bieker, L., Krajzewicz, D., Morra, A., Michelacci, C., Cartolano, F. (2015). Traffic Simulation for All: A Real World Traffic Scenario from the City of Bologna, in: Behrisch, M., Weber, M. (Eds.), Modeling Mobility with Open Data, Springer International Publishing, Cham, pp. 47-60. https://doi.org/10.1007/978-3-319-15024-6_4

Bigazzi, A.Y., Figliozzi, M.A. (2015). Roadway determinants of bicyclist exposure to volatile organic compounds and carbon monoxide. Transp. Res. Part D Transp. Environ. 41, 13-23. https://doi.org/10.1016/j.trd.2015.09.008

Borge, R., Santiago, J.L., de la Paz, D., Martín, F., Domingo, J., Valdés, C., Sánchez, B., Rivas, E., Rozas, M.T., Lázaro, S. (2018). Application of a short term air quality action plan in Madrid (Spain) under a high-pollution episode-Part II: Assessment from multi-scale modelling. Sci. Total Environ. 1574-1584. https://doi.org /10.1016/j.scitotenv.2018.04.323

Borowska-Stefańska, M., Kowalski, M., Wiśniewski, S. (2019). Wewnętrzna samochodowa dostępność transportowa Łodzi w świetle pomiarów z Inteligentnych Systemów Transportowych. PG 7-24. https://doi.org/10.4467/20833113PG.19.017.11485

Borowska-Stefańska, M., Kowalski, M., Kurzyk, P., Mikušová, M., Wiśniewski, S. (2021a). Privileging electric vehicles as an element of promoting sustainable urban mobility-Effects on the local transport system in a large metropolis in Poland. Energies 14, 3838. https://doi.org/ 10.3390/en14133838

Borowska-Stefańska, M., Kowalski, M., Kurzyk, P., Wiśniewski, S. (2021b). Application of intelligent transportation systems in analyses of human spatial mobility in cities. Prace Komisji PTG in print. https://doi.org/10.4467/2543859XPKG.21.001.14944

Brunekreef, B., Beelen, R., Hoek, G., Schouten, L., Bausch-Goldbohm, S., Fischer, P., Armstrong, B., Hughes, E., Jerrett, M., van den Brandt, P. (2009). Effects of long-term exposure to trafficrelated air pollution on respiratory and cardiovascular mortality in the Netherlands: The NLCS AIR study. Res. Rep. Health Eff. Inst. 139, 5-71; discussion 73-89.

Burnos, P., Gajda, J., Marszałek, Z., Piwowar, P., Sroka, R., Stencel, M., Żegleń, T. (2011). Road traffic parameters measuring system with variable structure. Metrol. Meas. Syst. 18, 659-666. https://doi.org/10.2478/v10178-011-0062-8

Charabi, Y., Abdul-Wahab, S., Al-Rawas, G., Al-Wardy, M., Fadlallah, S. (2018). Investigating the impact of monsoon season on the dispersion of pollutants emitted from vehicles: A case study of Salalah City, Sultanate of Oman. Transp. Res. Part D Transp. Environ. 59, 108-120. https://doi.org/10.1016/j.trd.2017.12.019

Chen, Z., Hao, X., Zhang, X., Chen, F. (2021). Have traffic restrictions improved air quality? A shock from COVID-19. J. Cleaner Prod. 279, 123622. https://doi.org/10.1016/j.jclepro.2020.123622

Clougherty, J.E., Wright, R.J., Baxter, L.K., Levy, J.I. (2008). Land use regression modeling of intraurban residential variability in multiple traffic-related air pollutants. Environ. Health 7, 17. https://doi.org/10.1186/1476-069X-7-17

Dankowska, M. (2016). Śródmiejski krajobraz kulturowy w dokumentach planistycznych, na przykładzie strefy wielkomiejskiej w Łodzi/Downtown Cultural Landscape in Planning 
Documents on the Example of the Urban Zone in Lodz. Studia KPZK.

de Almeida Albuquerque, T.T., de Fátima Andrade, M., Ynoue, R.Y., Moreira, D.M., Andreão, W.L., Dos Santos, F.S., Nascimento, E.G.S. (2018). WRF-SMOKE-CMAQ modeling system for air quality evaluation in São Paulo megacity with a 2008 experimental campaign data. Environ. Sci. Pollut. Res. 25, 36555-36569. https://doi.org/10.1007/s11356-018-3583-9

de Fatima Andrade, M., Kumar, P., de Freitas, E.D., Ynoue, R.Y., Martins, J., Martins, L.D., Nogueira, T., Perez-Martinez, P., de Miranda, R.M., Albuquerque, T. (2017). Air quality in the megacity of São Paulo: Evolution over the last 30 years and future perspectives. Atmos. Environ. 159, 66-82. https://doi.org/10.1016/j.atmosenv.2017.03.051

Duque, L., Relvas, H., Silveira, C., Ferreira, J., Monteiro, A., Gama, C., Rafael, S., Freitas, S., Borrego, C., Miranda, A. (2016). Evaluating strategies to reduce urban air pollution. Atmos. Environ. 127, 196-204. https://doi.org/10.1016/j.atmosenv.2015.12.043

Elangasinghe, M., Dirks, K., Singhal, N., Costello, S., Longley, I., Salmond, J. (2014). A simple semiempirical technique for apportioning the impact of roadways on air quality in an urban neighbourhood. Atmos. Environ. 83, 99-108. https://doi.org/10.1016/j.atmosenv.2013.11.005

Ferreira, F., Tente, H., Torres, P., Cardoso, S., Palma-Oliveira, J.M. (2000). Air quality monitoring and management in Lisbon. Environ. Monit. Assess. 65, 443-450. https://doi.org/10.1023/A: 1006433313316

Fu, M., Kelly, J.A., Clinch, J.P. (2017). Estimating annual average daily traffic and transport emissions for a national road network: A bottom-up methodology for both nationally-aggregated and spatially-disaggregated results. J. Transp. Geogr. 58, 186-195. https://doi.org/10.1016/j. jtrangeo.2016.12.002

Fu, X., Xiang, S., Liu, Y., Liu, J., Yu, J., Mauzerall, D.L., Tao, S. (2020). High-resolution simulation of local traffic-related $\mathrm{NO}_{x}$ dispersion and distribution in a complex urban terrain. Environ. Pollut. 263, 114390. https://doi.org/10.1016/j.envpol.2020.114390

Gajda, J., Sroka, R., Stencel, M., Wajda, A., Zeglen, T. (2001). A vehicle classification based on inductive loop detectors, in: IMTC 2001. Proceedings of the 18th IEEE Instrumentation and Measurement Technology Conference. Rediscovering Measurement in the Age of Informatics (Cat. No.01CH 37188), Presented at the IMTC 2001. IEEE, Budapest, Hungary, pp. 460-464. https://doi.org/10.1109/IMTC.2001.928860

Gautam, S. (2020). COVID-19: air pollution remains low as people stay at home. Air. Qual. Atmos. Health 13, 853-857. https://doi.org/10.1007/s11869-020-00842-6

Gómez, C., González, C., Osses, M., Aristizábal, B. (2018). Spatial and temporal disaggregation of the on-road vehicle emission inventory in a medium-sized Andean city. Comparison of GIS-based top-down methodologies. Atmos. Environ. 179, 142-155. https://doi.org/10.1016/j.atmosenv. 2018.01.049

Gualtieri, G., Crisci, A., Tartaglia, M., Toscano, P., Gioli, B. (2015). A statistical model to assess air quality levels at urban sites. Water Air Soil. Pollut. 226, 1-15. https://doi.org/10.1007/s11270015-2663-4

Gualtieri, G., Brilli, L., Carotenuto, F., Vagnoli, C., Zaldei, A., Gioli, B. (2020). Quantifying road traffic impact on air quality in urban areas: A Covid19-induced lockdown analysis in Italy. Environ. Pollut. 267, 115682. https://doi.org/10.1016/j.envpol.2020.115682

Guttikunda, S.K., Nishadh, K., Gota, S., Singh, P., Chanda, A., Jawahar, P., Asundi, J. (2019). Air quality, emissions, and source contributions analysis for the Greater Bengaluru region of India. Atmos. Pollut. Res. 10, 941-953. https://doi.org/10.1016/j.apr.2019.01.002

Hao, Y., Flowers, H., Monti, M.M., Qualters, J.R. (2012). US census unit population exposures to ambient air pollutants. Int. J. Health Geogr. 11, 3. https://doi.org/10.1186/1476-072X-11-3

Holnicki, P., Kałuszko, A., Trapp, W. (2016). An urban scale application and validation of the CALPUFF model. Atmos. Pollut. Res. 7, 393-402. https://doi.org/10.1016/j.apr.2015.10.016

Hueper, J., Dervisoglu, G., Muralidharan, A., Gomes, G., Horowitz, R., Varaiya, P. (2009). Macroscopic modeling and simulation of freeway traffic flow. IFAC Proc. Vol. 42, 112-116. https://doi.org/10.3182/20090902-3-US-2007.0078

Iqbal, A., Afroze, S., Rahman, M. (2020). Vehicular PM emissions and urban public health sustainability: A probabilistic analysis for Dhaka City. Sustainability 12, 6284. https://doi.org/ 10.3390/su12156284

Izquierdo, R., Dos Santos, S.G., Borge, R., De La Paz, D., Sarigiannis, D., Gotti, A., Boldo, E. (2020). 
Health impact assessment by the implementation of Madrid City air-quality plan in 2020. Environ. Res. 183, 109021. https://doi.org/10.1016/j.envres.2019.109021

Jenkins, N., Legassick, W., Sadler, L., Sokhi, R. (1970). Correlation Between NO and NO, Roadside Concentrations, Traffic Volumes and Local Meteorology at a Major London Route. WIT Trans. Ecol. Environ. 405-412.

Khan, J., Ketzel, M., Kakosimos, K., Sørensen, M., Jensen, S.S. (2018). Road traffic air and noise pollution exposure assessment-A review of tools and techniques. Sci. Total Environ. 634, 661676. https://doi.org/10.1016/j.scitotenv.2018.03.374

Khan, S., Hassan, Q. (2020). Review of developments in air quality modelling and air quality dispersion models. J. Environ. Eng. Sci. 16, 1-10. https://doi.org/10.1680/jenes.20.00004

Kheirbek, I., Haney, J., Douglas, S., Ito, K., Matte, T. (2016). The contribution of motor vehicle emissions to ambient fine particulate matter public health impacts in New York City: A health burden assessment. Environ. Health 15, 89. https://doi.org/10.1186/s12940-016-0172-6

Kim, S., Park, D., Heo, T.Y., Kim, H., Hong, D. (2016). Estimating vehicle miles traveled (VMT) in urban areas using regression kriging. J. Adv. Transp. 50, 769-785. https://doi.org/10.1002/atr.1374

Kingham, S., Longley, I., Salmond, J., Pattinson, W., Shrestha, K. (2013). Variations in exposure to traffic pollution while travelling by different modes in a low density, less congested city. Environ. Pollut. 181, 211-218. https://doi.org/10.1016/j.envpol.2013.06.030

Klatko, T.J., Saeed, T.U., Volovski, M., Labi, S., Fricker, J.D., Sinha, K.C. (2017). Addressing the local-road VMT estimation problem using spatial interpolation techniques. J. Transp. Eng. A: Syst. 143, 04017038. https://doi.org/10.1061/JTEPBS.0000064

Kowalski, M., Wiśniewski, S. (2017). Natężenie ruchu a zagospodarowanie Łodzi-zarys problematyki w świetle danych z Obszarowego Systemu Sterowania Ruchem. Prace Komisji Geografii Komunikacji PTG. 20, 20-36. https://doi.org/10.4467/2543859XPKG.17.022.8028

Krishnan, R.M., Adar, S.D., Szpiro, A.A., Jorgensen, N.W., Van Hee, V.C., Barr, R.G., O'Neill, M.S., Herrington, D.M., Polak, J.F., Kaufman, J.D. (2012). Vascular responses to long-and short-term exposure to fine particulate matter: MESA Air (Multi-Ethnic Study of Atherosclerosis and Air Pollution). J. Am. Coll. Cardiol. 60, 2158-2166. https://doi.org/10.1016/j.jacc.2012.08.973

Kruskal, J.B., Wish, M. (1978). Multidimensional scaling. Sage Publications, Beverly Hills, CA.

Kumar, A., Mishra, R.K., Sarma, K. (2020). Mapping spatial distribution of traffic induced criteria pollutants and associated health risks using kriging interpolation tool in Delhi. J. Transp. Health. 18, 100879. https://doi.org/10.1016/j.jth.2020.100879

Le, N.H., Ly, B.T., Thai, P.K., Pham, G.H., Ngo, I.H., Do, V.N., Le, T.T., Nhu, L.V., Son, H.D., Nguyen, Y.L.T. (2021). Assessing the Impact of Traffic Emissions on Fine Particulate Matter and Carbon Monoxide Levels in Hanoi through COVID-19 Social Distancing Periods. Aerosol Air Qual. Res. 21, 210081. https://doi.org/10.4209/aaqr.210081

Li, J., Van Zuylen, H.J., Wei, G. (2014). Diagnosing and interpolating loop detector data errors with probe vehicle data. Transp. Res. Rec. 2423, 61-67. https://doi.org/10.3141/2423-08

Liu, J., Han, K., Chen, X.M., Ong, G.P. (2019). Spatial-temporal inference of urban traffic emissions based on taxi trajectories and multi-source urban data. Transp. Res. Part C Emerg. 106, 145165. https://doi.org/10.1016/j.trc.2019.07.005

MacNaughton, P., Melly, S., Vallarino, J., Adamkiewicz, G., Spengler, J.D. (2014). Impact of bicycle route type on exposure to traffic-related air pollution. Sci. Total Environ. 490, 37-43. https://doi.org/10.1016/j.scitotenv.2014.04.111

Mardia, K., Kent, J., Bibby, J. (1979). Multivariate analysis. Academic Press, London. 15, 518.

Miri, M., Ghaneian, M.T., Gholizadeh, A., YazdaniAvval, M., Nikoonahad, A. (2016). Assessment of Spatial Analysis Methods in Mapping of Air Pollution in Mashhad. J. Environ. Health Eng. 3, 143-154. http://doi.org/10.18869/acadpub.jehe.3.2.143

Ntziachristos, L., Samaras, Z. (2020). EMEP/EEA air pollutant emission inventory guidebook 2019 - Update Oct. 2020. European Environment Agency.

Pan, L., Yao, E., Yang, Y. (2016). Impact analysis of traffic-related air pollution based on real-time traffic and basic meteorological information. J. Environ. Manage. 183, 510-520. http://doi.org/10.1016/j.jenvman.2016.09.010

Pasquier, A., André, M. (2017). Considering criteria related to spatial variabilities for the assessment of air pollution from traffic. Transp. Res. Procedia 25, 3354-3369. https://doi.org/ 10.1016/j.trpro.2017.05.210 
Perez-Martinez, P.J., Miranda, R.M. (2015). Temporal distribution of air quality related to meteorology and road traffic in Madrid. Environ. Monit. Assess. 187, 220. https://doi.org/ 10.1007/s10661-015-4452-3

Phillips, B.B., Bullock, J.M., Osborne, J.L., Gaston, K.J. (2021). Spatial extent of road pollution: A national analysis. Sci. Total Environ. 773, 145589. https://doi.org/10.1016/j.scitotenv.2021. 145589

Pinto, J.A., Kumar, P., Alonso, M.F., Andreao, W.L., Pedruzzi, R., Espinosa, S.I., de Almeida Albuquerque, T.T. (2020). Kriging method application and traffic behavior profiles from local radar network database: A proposal to support traffic solutions and air pollution control strategies. Sustain. Cities Soc. 56, 102062. https://doi.org/10.1016/j.scs.2020.102062

Qu, H., Lu, X., Liu, L., Ye, Y. (2019). Effects of traffic and urban parks on $\mathrm{PM}_{10}$ and $\mathrm{PM}_{2.5}$ mass concentrations. Energy Sources Part A https://doi.org/10.1080/15567036.2019.1672833

Quiros, D.C., Lee, E.S., Wang, R., Zhu, Y. (2013). Ultrafine particle exposures while walking, cycling, and driving along an urban residential roadway. Atmos. Environ. 73, 185-194. https://doi.org/10.1016/j.atmosenv.2013.03.027

Ranjbari, M., Esfandabadi, Z.S., Zanetti, M.C., Scagnelli, S.D., Siebers, P.O., Aghbashlo, M., Peng, W., Quatraro, F., Tabatabaei, M. (2021). Three pillars of sustainability in the wake of COVID19: A systematic review and future research agenda for sustainable development. J. Cleaner Prod. 126660. https://doi.org/10.1016/j.jclepro.2021.126660

Ravina, M., Esfandabadi, Z.S., Panepinto, D., Zanetti, M. (2021). Traffic-induced atmospheric pollution during the COVID-19 lockdown: Dispersion modeling based on traffic flow monitoring in Turin, Italy. J. Cleaner Prod. 317, 128425. https://doi.org/10.1016/j.jclepro.2021.128425

Rossi, R., Ceccato, R., Gastaldi, M. (2020). Effect of road traffic on air pollution. Experimental evidence from COVID-19 lockdown. Sustainability 12, 8984. https://doi.org/10.3390/su12218984

Şahin, Ü.A. (2020). The effects of COVID-19 measures on air pollutant concentrations at urban and traffic sites in Istanbul. Aerosol Air Qual. Res. 20, 1874-1885. https://doi.org/10.4209/ aaqr.2020.05.0239

Selby, B., Kockelman, K. (2011). Spatial prediction of AADT in unmeasured locations by universal kriging.

Selby, B., Kockelman, K.M. (2013). Spatial prediction of traffic levels in unmeasured locations: applications of universal kriging and geographically weighted regression. J. Transp. Geogr. 29, 24-32. https://doi.org/10.1016/j.jtrangeo.2012.12.009

Shahbazi, H., Ganjiazad, R., Hosseini, V., Hamedi, M. (2017). Investigating the influence of traffic emission reduction plans on Tehran air quality using WRF/CAMx modeling tools. Transp. Res. Part D Transp. Environ. 57, 484-495. https://doi.org/10.1016/j.trd.2017.08.001

Shahbazi, H., Hosseini, V. (2020). Impact of mobile source emission inventory adjustment on air pollution photochemical model performance. Urban Clim. 32, 100618. https://doi.org/ 10.1016/j.uclim.2020.100618

Shamo, B., Asa, E., Membah, J. (2015). Linear spatial interpolation and analysis of annual average daily traffic data. J. Comput. Civ. Eng. 29, 04014022. https://doi.org/10.1061/(ASCE)CP.19435487.0000281

Shen, L., Hadi, M. (2013). Practical approach for travel time estimation from point traffic detector data. J. Adv. Transp. 47, 526-535. https://doi.org/10.1002/atr.180

Shi, K., Di, B., Zhang, K., Feng, C., Svirchev, L. (2018). Detrended cross-correlation analysis of urban traffic congestion and $\mathrm{NO}_{2}$ concentrations in Chengdu. Transp. Res. Part D Transp. Environ. 61, 165-173. https://doi.org/10.1016/j.trd.2016.12.012

Shukla, K., Kumar, P., Mann, G.S., Khare, M. (2020). Mapping spatial distribution of particulate matter using Kriging and Inverse Distance Weighting at supersites of megacity Delhi. Sustain. Cities Soc. 54, 101997. https://doi.org/10.1016/j.scs.2019.101997

Son, J.Y., Bell, M.L., Lee, J.T. (2010). Individual exposure to air pollution and lung function in Korea: Spatial analysis using multiple exposure approaches. Environ. Res. 110, 739-749. https://doi.org/10.1016/j.envres.2010.08.003

Song, Y., Wang, X., Wright, G., Thatcher, D., Wu, P., Felix, P. (2018). Traffic volume prediction with segment-based regression kriging and its implementation in assessing the impact of heavy vehicles. IEEE. Trans. Intell. Transp. Syst. 20, 232-243. http://doi.org/10.1109/TITS.2018. 2805817 
Sun, D.J., Zhang, K., Shen, S. (2018). Analyzing spatiotemporal traffic line source emissions based on massive didi online car-hailing service data. Transp. Res. Part D Transp. Environ. 62, 699714. https://doi.org/10.1016/j.trd.2018.04.024

TomTom (2021). https://www.tomtom.com/en_gb/traffic-index/

Van Beers, W.C., Kleijnen, J.P. (2004). Kriging interpolation in simulation: A survey. Proceedings of the 2004 Winter Simulation Conference. https://doi.org/10.1109/WSC.2004.1371308

Wang, X., Kockelman, K.M. (2009). Forecasting network data: Spatial interpolation of traffic counts from Texas data. Transp. Res. Rec. 2105, 100-108. https://doi.org/10.3141/2105-13

Wang, Y., Yuan, Y., Wang, Q., Liu, C., Zhi, Q., Cao, J. (2020a). Changes in air quality related to the control of coronavirus in China: Implications for traffic and industrial emissions. Sci. Total Environ. 731, 139133. https://doi.org/10.1016/j.scitotenv.2020.139133

Wang, Z., Zhou, H., Si, Y., Li, Y. (2020b). Role of traffic emission on temporal and spatial characteristics of pollutant concentration on urban road network: A case of Beijing. J. Adv. Transp. 2020, 8883697. https://doi.org/10.1155/2020/8883697

Weichenthal, S., Van Ryswyk, K., Kulka, R., Sun, L., Wallace, L., Joseph, L. (2015). In-vehicle exposures to particulate air pollution in Canadian metropolitan areas: The urban transportation exposure study. Environ. Sci. Technol. 49, 597-605. https://doi.org/10.1021/es504043a

World Health Organization (WHO) (2020). WHO Director-General's opening remarks at the media briefing on COVID-19. https://www.who.int/director-general/speeches/detail/who-directorgeneral-s-opening-remarks-at-the-media-briefingon-covid-19-11-march-2020

World Health Organization (WHO) (2021). WHO global air quality guidelines: Particulate matter ( $\mathrm{PM}_{2.5}$ and $\left.\mathrm{PM}_{10}\right)$, ozone, nitrogen dioxide, sulfur dioxide and carbon monoxide. World Health Organization. https://apps.who.int/iris/handle/10665/345329

Xiang, J., Austin, E., Gould, T., Larson, T., Shirai, J., Liu, Y., Marshall, J., Seto, E. (2020). Impacts of the COVID-19 responses on traffic-related air pollution in a Northwestern US city. Sci. Total Environ. 747, 141325. https://doi.org/10.1016/j.scitotenv.2020.141325

Yang, H., Yang, J., Han, L.D., Liu, X., Pu, L., Chin, S.M., Hwang, H.I. (2018). A Kriging based spatiotemporal approach for traffic volume data imputation. PloS One. 13, e0195957. https://doi.org/10.1371/journal.pone.0195957

Zambrano, J.L., Calafate, C.T., Soler, D., Cano, J.C., Manzoni, P. (2016). Using real traffic data for its simulation: Procedure and validation, 2016 Intl IEEE Conferences on Ubiquitous Intelligence \& Computing, Advanced and Trusted Computing, Scalable Computing and Communications, Cloud and Big Data Computing, Internet of People, and Smart World Congress (UIC/ATC/ScalCom/CBDCom/loP/SmartWorld). 161-170. https://doi.org/10.1109/UIC-ATCScalCom-CBDCom-IoP-SmartWorld.2016.0045

Zou, H., Yue, Y., Li, Q., Yeh, A.G. (2012). An improved distance metric for the interpolation of linkbased traffic data using kriging: a case study of a large-scale urban road network. Int. J. Geogr. Inf. Sci. 26, 667-689. https://doi.org/10.1080/13658816.2011.609488

Zuurbier, M., Hoek, G., Oldenwening, M., Lenters, V., Meliefste, K., Van Den Hazel, P., Brunekreef, B. (2010). Commuters' exposure to particulate matter air pollution is affected by mode of transport, fuel type, and route. Environ. Health Perspect. 118, 783-789. https://doi.org/ 10.1289/ehp.0901622

Zwack, L.M., Paciorek, C.J., Spengler, J.D., Levy, J.I. (2011). Modeling spatial patterns of trafficrelated air pollutants in complex urban terrain. Environ. Health Perspect. 119, 852-859. https://doi.org/10.1289/ehp.1002519 